\title{
Adsorption and Leaching Potential of Imidacloprid Pesticide through Alluvial Soil
}

\author{
Muhammad Ashraf Bajeer, Shafi Muhammad Nizamani*, \\ Syed Tufail Hussain Sherazi, Muhammad Iqbal Bhanger \\ National Centre of Excellence in Analytical Chemistry, University of Sindh, Jamshoro, Pakistan \\ Email: *drshafi.nizamani@gmail.com
}

Received April 27, 2012; revised May 28, 2012; accepted June 3, 2012

\begin{abstract}
This study was aimed to assess the adsorption and leaching potential of imidacloprid pesticide in column and field soil. To understand mechanism of adsorption and factors affecting, the experiments were carried out under laboratory and field conditions. Adsorption study was divided into kinetic and equilibrium sections. The evaluation of kinetic data was done through pseudo first and second order models. It was found that kinetic adsorption of imidacloprid on soil followed pseudo second order with rate constant value of $4.333 \mathrm{mg} / \mathrm{g} / \mathrm{h}$. Langmuir and Freundlich isotherms were used to explain equilibrium adsorption, from these isotherms it was evaluated that Freundlich isotherm was obeyed well with adsorption capacity of $2.190-4.573 \mathrm{~mol} / \mathrm{g}$. Leaching study was performed in laboratory using column made of polyvinyl chloride having $30 \mathrm{~cm}$ length. Known amount of imidacloprid pesticide was applied to column left for adsorption and then eluted with $500 \mathrm{~mL}$ water in five equal portions. These water portions and soil of column which was divided into three sections were analyzed by HPLC. The result revealed that the concentration of imidacloprid was decreased from $0.481 \mathrm{ppm}$ in first portion of water to $0.327 \mathrm{ppm}$ in last portion of water while $0.783 \mathrm{ppm}$ in first section of column soil to $0.038 \mathrm{ppm}$ in last section of column soil. In field the leaching power of imidacloprid was observed up to 60 $\mathrm{cm}$ depth, its concentration decreased with soil depth. It was $3.311 \mathrm{ppm}$ in first portion of soil and $0.357 \mathrm{ppm}$ in last portion of soil. The leaching potential of imidacloprid pesticide up to $60 \mathrm{~cm}$ soil depth was due to less organic matter, sandy texture, alkaline $\mathrm{pH}$, and low cation exchange capacity.
\end{abstract}

Keywords: Pesticide; Adsorption; Leaching; Imidacloprid; Soil

\section{Introduction}

The utilization and production of pesticides are increasing worldwide day by day. It is important to know that when pesticides are applied to field, as the only small portion reaches to its target and remaining a large part is released into the environment. That may leads to some problems, such as toxicity to non-target organisms, leaching and accumulation. Polluted soil, surface and ground waters involve risk to the environment and also to human health due to possible direct or indirect exposures.

Imidacloprid, 1-(6-chloro-3-pyridinylmethyl)-N-nitroimidazolidin-2-ylideneamine, is a systemic chloronicotinoid insecticide which is used for soils, seeds and foliar applications for the control of sucking insects, including rice hoppers, aphids, thrips, whiteflies, termites, turf insects, soil insects, chewing insects, some beetles, scales, psyllids, plant bugs, and other various harmful pest species including resistant strains. It is most commonly used on rice, cereal, maize, sunflowers, potatoes and vegeta-

\footnotetext{
*Corresponding author.
}

bles. It is applied as a seed and soil treatment, crop and structural treatment, and a topical flea control treatment on domestic pets [1-5]. It is also used for animal health applications to control parasites like fleas of dogs and cats [6]. It kills insects via ingestion or contact by disrupting the nervous system of an insect pest through interfering with the transmission of stimuli in the insect's nervous system. This pesticide causes an obstruction in the nicotinergic neuronal pathway which is more abundant in insects than in warm-blooded animals, making the pesticide much more toxic to insects than to warmblooded animals. It is sold in market with various brand names such as Pestidor, Concord, Pencidor, Ningo, Imicon, Confidor, Crown, Launcher, Jozer, Simida and Agrotech.

The environmental fate of pesticides is mainly regulated by their behaviour in soil where various physicochemical and biological processes control their dissipation and movement towards other environmental compartments like air, water and biota $[7,8]$. The mobility of a pesticide in soil is determined by the extent and strength 
of sorption, which is influenced by various soil physicochemical properties $[9,10]$. Sorption is one of the most important processes that affects the fate of pesticides in the soil and determines their distribution in the soil/water environment, it is widely used to describe the process of a pesticide partitioning between water solution and soil [11]. Sorption also determines availability of pesticides in the soil solution that governs the amount of pesticide that is available for uptake by plants and the effectiveness of pesticides [12]. It is reported that adsorption is one of the most important processes which controls all other processes such as their movement, persistence and degradation and determines the fate of pesticides in soil systems [13]. Extensive research has been done on imidacloprid in relation to its mobility and leaching potential in soils [14-16].

But above studies have been conducted in acidic soils whereas Sindh soils are sodic and alkaline in nature. There was no any such studies have been conducted on its adsorption behavior in this type of soil. The present study was undertaken to evaluate the adsorption, and leaching of imidacloprid in sodic and alkaline soil.

\section{Materials and Methods}

\subsection{Chemicals}

Imidacloprid standard of high purity $(99.4 \%)$ was obtained from Bayer Crop Science and commercial imidacloprid was purchased from local market HyderabadSindh, Pakistan. Imidacloprid stock solution was prepared in acetonitrile and other working solutions were prepared by diluting the stock solution.

\subsection{Study Area}

The study area was selected at the field of National Centre of Excellence in Analytical Chemistry, University of Sindh, Jamshoro, Sindh-Pakistan. Okra crop was sown in first week of November 2010 on the experimental field; plot size was $60 \times 60$ feet. One month after sowing okra was sprayed with imidacloprid at the recommended dose. Subsequently imidacloprid was sprayed two times per week and this makes a total of sixteen sprays until final harvest.

\subsection{Soil Sampling}

For laboratory study the inert soil samples were collected from the 0 to $15 \mathrm{~cm}$ soil depth, air-dried, and ground to pass through a $2 \mathrm{~mm}$ sieve. These soil samples were stored in plastic bags at room temperature. The standard methods were used to determine physicochemical properties of the soil, which are given in Table 1. The $\mathrm{pH}$ of soil was determined in a 1:1.25 soil to water suspension using a glass electrode, organic matter by Walkley-Black
Table 1. Physicochemical properties of the soil.

\begin{tabular}{lc}
\hline Parameter & Value \\
\hline $\mathrm{pH}$ & $8.46 \pm 0.01$ \\
Electrical Conductivity $(\mu \mathrm{S} / \mathrm{cm})$ & $560 \pm 0.25$ \\
Cation Exchange Capacity $(\mathrm{meq} / 100 \mathrm{~g})$ & $18 \pm 0.21$ \\
Organic Matter (\%) & $0.899 \pm 0.01$ \\
Total Organic Carbon (\%) & $0.522 \pm 0.001$ \\
Sand (\%) & $74.75 \pm 0.68$ \\
Slit (\%) & $18.15 \pm 0.24$ \\
Clay (\%) & $7.1 \pm 0.17$ \\
Classification & Sandy Loam \\
\hline
\end{tabular}

method and soil texture by hydrometer method.

For field study sampling was done from four locations, selected at random, of okra plot. From each sampling location, four soil samples were collected; first soil sample was collected from 0 to $10 \mathrm{~cm}$, second from 11 to 20 $\mathrm{cm}$, third from 21 to $30 \mathrm{~cm}$ and fourth from 31 to $60 \mathrm{~cm}$ depth. These samples were properly labeled and stored in plastic bags in a freezer at $-10^{\circ} \mathrm{C}$ until extraction. In laboratory study, the experiment was carried out on leaching of pesticide through column and adsorption of pesticide on soil. While in field study the pesticide residue and leaching of pesticide in soil was known.

\subsection{Adsorption Study}

\subsubsection{Kinetic Adsorption Study}

For kinetic adsorption study, $5 \mathrm{~g}$ of soil was mixed with $100 \mathrm{~mL}$ of $100 \mathrm{ppm}$ standard imidacloprid solution in a $250 \mathrm{~mL}$ conical flask. This mixture was shaken on an orbital shaker at the speed of $150 \mathrm{rpm}$ for a period of 24 hours at room temperature. $5 \mathrm{~mL}$ of sample was collected from flask at time intervals of $0,0.25,0.5,1,2,4,8,16$ and 24 hours. The collected samples were extracted with $10 \mathrm{~mL}$ of methylene chloride solution in separating funnel. The water layer was decanted carefully and the supernatant was extracted with $5 \mathrm{~mL}$ of methylene chloride for two more times. Finally, extracted samples were filtered and analyzed for residual pesticide concentration using HPLC.

\subsubsection{Equilibrium Adsorption Study}

For equilibrium adsorption study, $5 \mathrm{~g}$ of soil was mixed with different imidacloprid concentrations as $0.15,0.25$, $1,2,5,10,25,50$ and $100 \mathrm{ppm}$ in $250 \mathrm{~mL}$ conical flasks. Then reaction mixtures were shaken on an orbital shaker at the speed of $150 \mathrm{rpm}$ for 6 hours (equilibrium time) at room temperature. After 6 hours, $5 \mathrm{~mL}$ of sample was taken from each conical flask and centrifuged at 3000 rpm for $15 \mathrm{~min}$; the supernatant was extracted with methylene chloride (as described above). Extracted samples 
were filtered and analyzed by HPLC. Same way a blank solution was also prepared to know the effect of imidacloprid adsorption on walls of conical flask.

\subsection{Column Leaching Study}

The column (30-cm length, 6-cm i.d.) was made from polyvinyl chloride pipe, fitted with $0.60 \mu \mathrm{m}$ nylon membrane. To prevent the soil loss from column to outside, wool was placed on nylon membrane. On first day column was filled with soil, soaked with distilled water and left for overnight. Next day imidacloprid $(5 \mathrm{mg}$ ) dissolved in $5 \mathrm{~mL}$ acetonitrile was applied to the surface of column and left for 24 hours. Then column was eluted with distilled water of $500 \mathrm{~mL}$ quantity at the flow rate of $100 \mathrm{~mL} / \mathrm{h}$ with the help of peristaltic pump into five portions of $100 \mathrm{~mL}$ each. After elution was over the soil of column was divided into three sections of $10 \mathrm{~cm}$ each to determine adsorbed pesticide on soil.

\subsection{Extraction of Soil and Water Samples}

$50 \mathrm{~g}$ of air dried soil was mixed with $50 \mathrm{~mL}$ acetonitrile in a $250 \mathrm{~mL}$ stoppered flask. The sample was equilibrated on a rotary shaker for 2 hour and the extract was filtered. Each $100 \mathrm{~mL}$ water portion eluted from column was mixed with $50 \mathrm{~mL}$ methylene chloride in a $250 \mathrm{~mL}$ separating funnel. The separating funnel was shaken vigorously for 5 minutes to ensure the complete mixing of two layers. After separation of two layers, methylene chloride layer containing pesticide residue was collected. These extracts (soil and water) were concentrated to 5 $\mathrm{mL}$ with stream of nitrogen and analyzed with HPLC instrument to know pesticide concentration present.

\subsection{Analytical Technique}

Analysis of imidacloprid was performed by HPLC Hitachi model L-6200 with UV-Vis detector model Hitachi L-4200.The selected wavelength was $254 \mathrm{~nm}$. The solvent compositions were acetonitrile and water as 70:30 using reverse phase C18 inertsil ODS-3 (250 $\mathrm{mm} \times 4.6$ $\mathrm{mm}$ ) column with flow rate of $1 \mathrm{~mL} \cdot \mathrm{min}^{-1}$ and injection volume was $20 \mu \mathrm{L}$. The retention time for imidacloprid was $5.22 \mathrm{~min}$.

\subsection{Percent Recovery}

Blank soil of $50 \mathrm{~g}$ weight was spiked with $0.1,0.5$ and 1 ppm imidacloprid standard solutions. The soil was mixed thoroughly for even distribution of pesticide and left for overnight so that the pesticide can be adsorbed completely. Then imidacloprid was extracted and analyzed as above. For calibration the imidacloprid standards from 0.01 to $10 \mathrm{ppm}$ concentration were run on HPLC. The percent recoveries of imidacloprid found in soil and wa- ter were $95.33 \% \pm 1.2 \%$ and $80.15 \% \pm 1.09 \%$ respectively.

\subsection{Limits of Detection and Quantification}

Limit of detection (LOD) of imidacloprid was calculated at a signal-to-signal ratio of 3 , while the limit of quantification (LOQ) was obtained at a signal-to-signal ratio of 10. The LOD and LOQ for imidacloprid were $0.4 \pm$ $0.002 \mu \mathrm{g} / \mathrm{kg}$ and $5 \pm 0.06 \mu \mathrm{g} / \mathrm{kg}$ respectively.

\section{Results and Discussion}

\subsection{Affect of Physicochemical Properties of Soil on Adsorption and Leaching of Imidacloprid Pesticide}

Sorption is one of the most important processes affecting the leaching of pesticides through soil because it controls the amount of pesticide available for transport. Physicochemical properties of soil can significantly affect pesticide transport and the potential for groundwater contamination [17]. These properties include soil texture, organic matter, $\mathrm{pH}$, cation exchange capacity, electrical conductance and moisture. The pesticide is more adsorbed to soil containing higher content of clay in its texture because the clay possesses a larger surface area $[18,19]$. As the texture of our soil was sandy loam containing 74.75\% sand, so adsorption of imidacloprid was less because sand particles have less surface area than clay or slit. Therefore higher leaching power of imidacloprid was seen in column and field study. In column experiment the imidacloprid was adsorbed on soil filled in column as well as leached with water by passing through $30 \mathrm{~cm}$ column length. While in field study the imidacloprid leached upto $60 \mathrm{~cm}$ depth showing its strong leaching power as reported in literature [20]. This leaching tendency of imidacloprid was observed in soil on which it was applied first time but in field where it is applied from many years the leaching power will be more as above researcher reported. Higher organic matter favors adsorption while reduces leaching capacity of imidacloprid pesticide $[21,22]$. The organic matter content of our studied soil was less $(0.899 \pm 0.01)$; therefore limited adsorption and more leaching of imidacloprid were seen. Organic matter is closely related to cation exchange capacity as it has the highest cation exchange capacity of all the soil constituents and a larger surface area, therefore higher amount of organic matter and cation exchange capacity increases adsorption and reduces leaching. Bansal in his study of three carbamate pesticides sorption had observed that, the addition of organic matter to soil increases soil organic carbon content and electrical conductivity while decreases $\mathrm{pH}$ [23]. He noticed that the adsorption was positively correlated with soil organic carbon and cation exchange capacity while negatively 
correlated with soil $\mathrm{pH}$. The effect of $\mathrm{pH}$ on adsorption of pesticide is that in acidic soils due to presence of a salt the stronger cation exchange mechanisms of chemisorption is favored hence adsorption is more as compared to basic soils having higher $\mathrm{pH}[24,25]$. The same trend was observed by Ping et al. that imidacloprid adsorption was usually higher under lower $\mathrm{pH}$ and/or lower temperature at same condition [26]. The $\mathrm{pH}$ of our soil was 8.46 (in basic range), hence adsorption was low and leaching was more. The higher electrical conductivity value of soil enhances water retention by increasing the osmotic potential of the soil, thereby increasing the contact-time for adsorption. Leaching and adsorption are inversely related to each other, the soil in which leaching is more and adsorption will be less means that soil possess less organic matter and light texture. The physicochemical properties of soil are shown in Table $\mathbf{1}$.

\subsection{Kinetic Adsorption Study}

Kinetic adsorption revealed the removal rate of solute which controls the residence time of the pesticide in the solid-solution interface. The kinetic adsorption has shown two clear regions as given in Figure 1; initially a very rapid adsorption up to four hour followed a slow adsorption region. The pseudo equilibrium was achieved within six hour and then a uniform adsorption of imidacloprid in soil was observed.

The imidacloprid was removed from solution during initial four hours, as reported in literature for different pesticides by various researchers $[27,28]$. The imidacloprid was adsorbed rapidly during first stage because the vacant sites are available in soil initially, followed by a slow migration and diffusion of imidacloprid molecules in soil [29].

The pseudo first order and pseudo second order kinetic models were used to observe that which model was best fitted to kinetic adsorption.

\subsubsection{Pseudo First Order Model}

First order rate constant was calculated by Equation (1).

$$
\log \left(\mathrm{q}_{\mathrm{e}}-\mathrm{q}_{\mathrm{t}}\right)=\log \mathrm{q}_{\mathrm{e}}-\mathrm{k}_{1} \cdot \mathrm{t} / 2.303
$$

where $\mathrm{q}_{\mathrm{e}}$ and $\mathrm{q}_{\mathrm{t}}$ are the amount of imidacloprid adsorbed $(\mathrm{mg} / \mathrm{g})$ at equilibrium and at time $\mathrm{t}(\mathrm{min})$ respectively while $k_{1}(1 / h)$ is the first order rate constant. Therefore first order rate constant $\mathrm{k}_{1}$ and $\mathrm{q}_{\mathrm{e}}$ were calculated from slope and intercept of plot $\log \left(\mathrm{q}_{\mathrm{e}}-\mathrm{q}_{\mathrm{t}}\right)$ versus t. This model was not followed by adsorption of imidacloprid.

\subsubsection{Pseudo Second Order Model}

Data was also examined through pseudo second order model given by Ho and McKay. Second order rate constant was calculated by Equation (2).

$$
\mathrm{t} / \mathrm{q}_{\mathrm{t}}=1 / \mathrm{k}_{2} \cdot \mathrm{q}_{\mathrm{e}}^{2}+\mathrm{t} / \mathrm{q}_{\mathrm{e}}
$$

Plot of $t / q_{t}$ versus $t$ had shown straight line with $R^{2}$ value 0.999 for imidacloprid as shown in Figure 2, from which it was concluded that kinetic adsorption of imidacloprid had closely correlate with pseudo second order model [30]. In chemisorption process, the pseudo second order is superior to pseudo-first order model because it deals with interaction of adsorbent-adsorbate through their valency forces. The rate constant values of both orders are shown in Table 2.

\subsection{Equilibrium Adsorption Study}

Adsorption isotherm studies were conducted at $28^{\circ} \mathrm{C}$ with an equilibrium time of $6 \mathrm{~h}$. Langmuir and Freundlich isotherm models were applied to calculate the isotherm constants and the maximum adsorption capacity of imidacloprid at nine different concentrations to evaluate its behavior clearly. These concentrations were $0.25,0.5,1$,

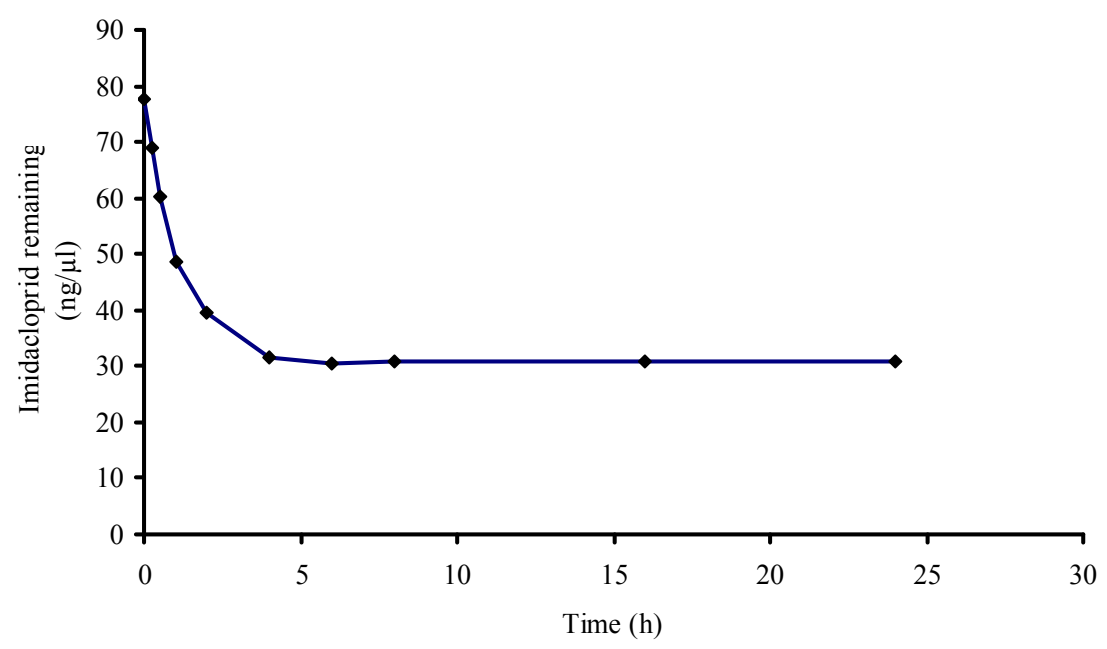

Figure 1. Kinetic adsorption of imidacloprid. 


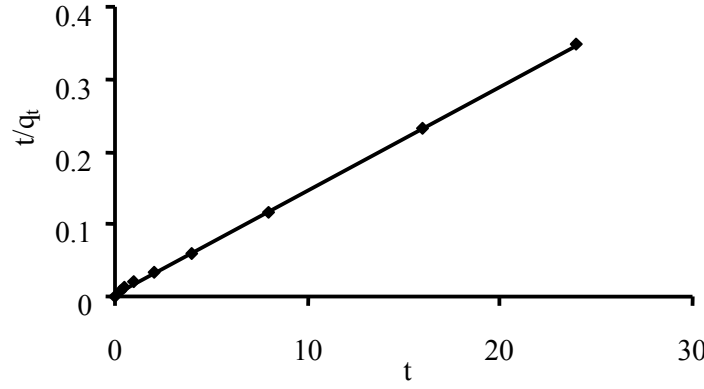

Figure 2. Pseudo second order plot for imidacloprid.

Table 2. Adsorption rates of imidacloprid.

\begin{tabular}{lc}
\hline Models applied & $\begin{array}{c}\text { Adsorption rate of } \\
\text { imidacloprid }\end{array}$ \\
\hline Pseudo first order $(1 / \mathrm{h})$ & $0.845 \pm 0.011$ \\
Pseudo second order $(\mathrm{mg} / \mathrm{g} / \mathrm{h})$ & $4.333 \pm 0.02$ \\
\hline
\end{tabular}

$2,5,10,25,50$ and $100 \mathrm{ppm}$.

\subsubsection{Langmuir Isotherm Model}

This model deals with monolayer and homogeneous adsorption because the adsorbed layer is one molecule in thickness, with adsorption occurring at fixed sites, which are identical and equivalent. Linear form of this model is given in Equation (3).

$$
\mathrm{Ce} / \mathrm{Cads}=1 / \mathrm{Qb}+\mathrm{Ce} / \mathrm{Q}
$$

where $\mathrm{Ce}$ is the equilibrium concentration of imidacloprid in solution (mol/L) and Cads is the amount of imidacloprid $(\mathrm{mol} / \mathrm{g})$ on soil surface, $\mathrm{Q}$ is the monolayer adsorption capacity, and b is Langmuir constant. The plot of $\mathrm{Ce} / \mathrm{Cads}$ against $\mathrm{Ce}$ gives langmuir isotherm which was not obeyed by adsorption of imidacloprid.

\subsubsection{Freundlich Isotherm Model}

Freundlich isotherm is related to the non-ideal and reversible adsorption, not limited to monolayer formation. Therefore it is applied to multilayer adsorption, with nonuniform distribution of adsorption heat and affinities over the heterogeneous surface. Linear form of this model is given as in Equation (4).

$$
\text { Log Cads }=\log \mathrm{A}+(1 / \mathrm{n}) \log \mathrm{Ce}
$$

where $\mathrm{A}$ is multilayer adsorption capacity and $\mathrm{n}$ is adsorption intensity. A plot of log Cads against Ce gives straight line showing that this model was obeyed by adsorption of imidacloprid [31] as shown in Figure 3. Freundlich isotherm was applied at both, lower $(0.25,0.5$, $1,2 \mathrm{ppm})$ and higher concentrations $(5,10,25,50$ and $100 \mathrm{ppm}$ ) as shown in Figures 3(a) and (b).

The parameters of both models are shown in Table 3. The $n$ value is 1.664 and 1.366 for imidacloprid in Freundlich isotherm, showing that adsorption process was favorable because $1<\mathrm{n}<10$ represents the favorability of

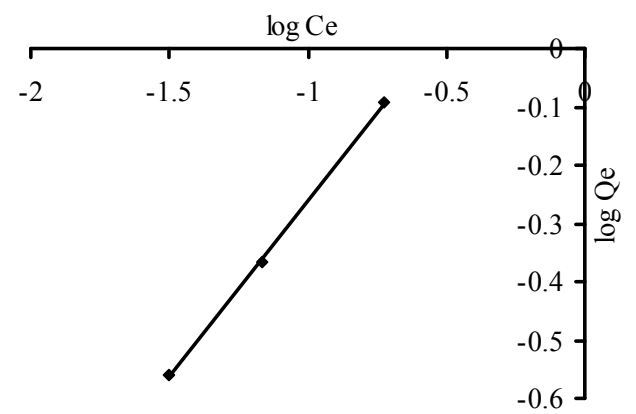

(a)

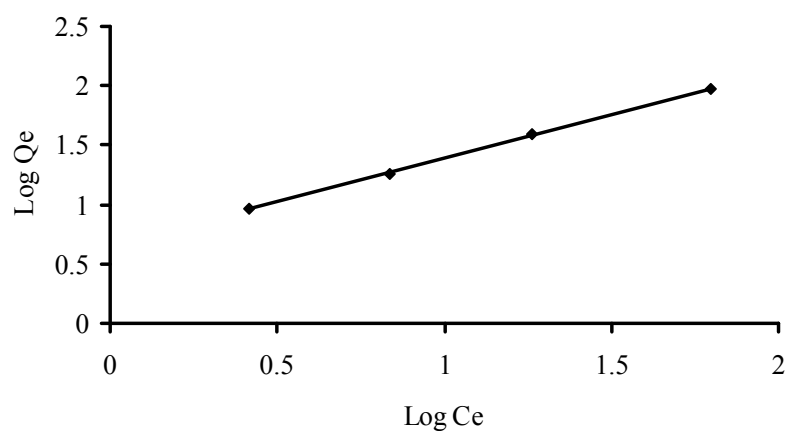

(b)

Figure 3. Freundlich isotherm for imidacloprid at (a) lower and (b) higher concentrations.

Table 3. Equilibrium adsorption isotherm values for imidacloprid pesticide.

\begin{tabular}{ccc}
\hline Isotherm & Isotherm parameter & Value \\
\hline Langmuir & $\mathrm{Q}(\mathrm{mol} / \mathrm{g})$ & $6.459 \times 10^{-4}$ \\
& $\mathrm{~b}$ & 0.179 \\
& $\mathrm{R}^{2}$ & 0.743 \\
Freundlich & $\mathrm{A}(\mathrm{mol} / \mathrm{g})$ & 2.190 \\
(at lower concentration) & $\mathrm{n}$ & 1.664 \\
& $\mathrm{R}^{2}$ & 0.999 \\
Freundlich & $\mathrm{A}(\mathrm{mol} / \mathrm{g})$ & 4.573 \\
(at higher concentration) & $\mathrm{N}$ & 1.366 \\
& $\mathrm{R}^{2}$ & 0.999 \\
\hline
\end{tabular}

adsorption [32].

\subsection{Column Leaching Study}

From water portions of column it was observed that the amount of imidacloprid pesticide eluted was more as compared to adsorbed on soil filled in column due to more water solubility of imidacloprid. The amount of imidacloprid was eluted in each portion of water but it was decreased from $0.481 \mathrm{ppm}$ in first portion of water to $0.327 \mathrm{ppm}$ in last portion of water. During this elution the pesticide has transported $30 \mathrm{~cm}$ column length due to 


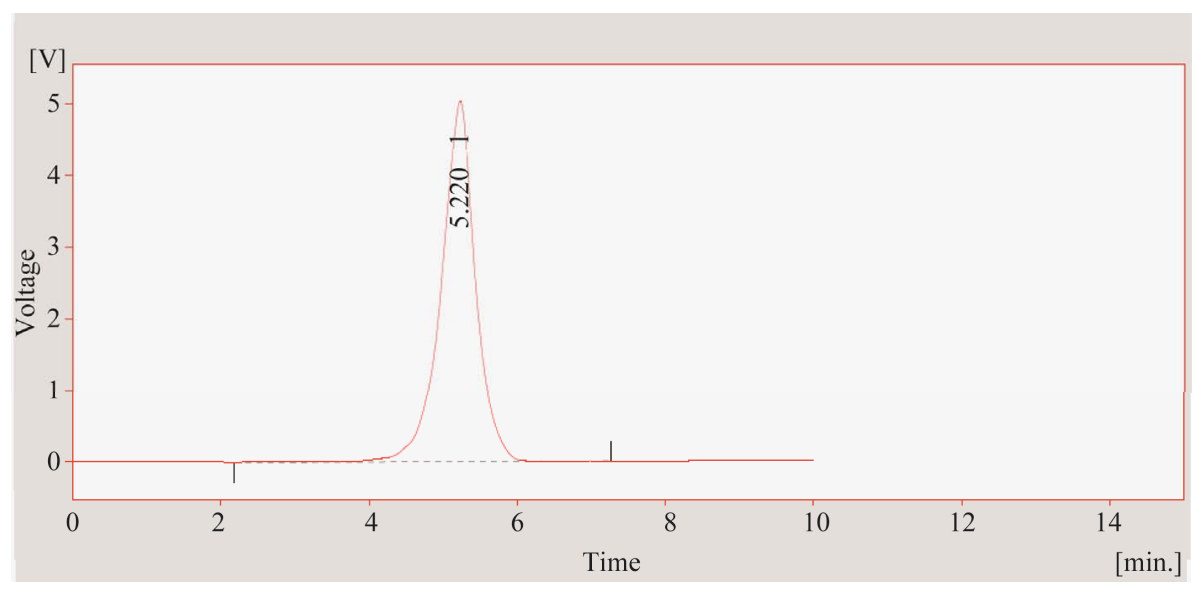

Figure 4. HPLC chromatogram showing peak for imidacloprid at retention time 5.201 min.

less organic matter content present in our soil, sandy texture and forcing power of water. The concentration of imidacloprid has decreased from $0.783 \mathrm{ppm}$ in first section of column soil to $0.038 \mathrm{ppm}$ in third section of column soil, showing both leaching and adsorption power of imidacloprid in column. The result is shown in Table 4. A representative chromatogram of imidacloprid is shown in Figure 4.

\subsection{Field Study}

Imidacloprid is mobile in the environment due to its weak adsorption on soil [33]; therefore in field it was leached upto $60 \mathrm{~cm}$ due to less organic matter content, sandy texture, low cation exchange capacity and basic $\mathrm{pH}$. The concentration of imidacloprid was decreased as we go down. It was $3.311 \mathrm{ppm}$ in first portion of soil having depth $0-10 \mathrm{~cm}, 1.276 \mathrm{ppm}$ in second portion of soil having depth $11-20 \mathrm{~cm}, 0.923 \mathrm{ppm}$ in third portion of soil having depth $21-30 \mathrm{~cm}$ and $0.357 \mathrm{ppm}$ in fourth portion of soil having depth $31-60 \mathrm{~cm}$. The results are shown in Table 5.

\section{Conclusion}

Present study suggests that the kinetic adsorption of imidacloprid on soil follows the second order kinetic model and the rate limiting step may be chemical adsorption, while equilibrium adsorption follows Freundlich isotherm describing the reversible, non-ideal and multilayer adsorption over the heterogeneous surface. From laboratory and field studies it was concluded that the leaching and adsorption power of imidacloprid in soil were dependent upon physicochemical properties of soil. In our soil the imidacloprid pesticide was leached up to $60 \mathrm{~cm}$ soil depth due to less organic matter, sandy texture, basic $\mathrm{pH}$, and low cation exchange capacity, otherwise it may be adsorbed on surface of soil. The soils in Sindh, Pakistan are alkaline and have low organic matter, while
Table 4. Imidacloprid leaching and adsorption through column.

\begin{tabular}{cc}
\hline Sample $(\mathrm{cm})$ & Imidacloprid concentration found $(\mathrm{ppm})$ \\
\hline Soil $0-10$ & $0.783 \pm 0.02$ \\
Soil $11-20$ & $0.102 \pm 0.011$ \\
Soil $21-30$ & $0.038 \pm 0.002$ \\
Water-01 & $0.481 \pm 0.002$ \\
Water-02 & $0.464 \pm 0.001$ \\
Water-03 & $0.362 \pm 0.001$ \\
Water-04 & $0.357 \pm 0.003$ \\
Water-05 & $0.327 \pm 0.001$ \\
\hline
\end{tabular}

Table 5. Imidacloprid residue in okra field soil.

\begin{tabular}{ccc}
\hline Soil depth (cm) & $\begin{array}{c}\text { Imidacloprid concentration } \\
\text { found (ppm) }\end{array}$ & $\begin{array}{c}\text { \% of imidacloprid in } \\
\text { each layer }\end{array}$ \\
\hline Soil 0 - 10 & $3.311 \pm 0.08$ & $56.434 \pm 0.09$ \\
Soil 11 - 20 & $1.276 \pm 0.09$ & $21.749 \pm 0.35$ \\
Soil 21 - 30 & $0.923 \pm 0.07$ & $15.732 \pm 0.04$ \\
Soil 31 - 60 & $0.357 \pm 0.02$ & $6.084 \pm 0.03$ \\
Grand Total & 5.867 & 100 \\
\hline
\end{tabular}

pesticide adsorption studies reported in literature have been conducted in soils having acidic $\mathrm{pH}$ and rich in organic matter. In basic soils with low organic matter, adsorption is low and leaching is more that we have pointed out here. More leaching is a potential threat to environment and whole food chain.

\section{Acknowledgements}

We thank the Department of Agriculture, Government of Sindh and National Centre of Excellence in Analytical Chemistry, University of Sindh, Jamshoro for the financial support of this work. 


\section{REFERENCES}

[1] R. Nauen, H. Hungenberg, B. Tollo, K. Tietjen and A. Elbert, "Antifeedant Effect, Biological Efficacy and High Affinity Binding of Imidacloprid to Acetylcholine Receptors in Myzus Persicae and Myzus Nicotianae," Pest Science, Vol. 53, No. 2, 1998, pp. 133-140.

[2] M. Y. Liu, B. Latli and J. E. Casida, "Imidacloprid Binding Site in Musca Nicotinic Acetylcholine Receptor: Interactions with Physostigmine and a Variety of Nicotinic Agonists with Chloropyridyl and Chlorothiazolyl Substituents," Pesticide Biochemistry and Physiology, Vol. 52, No. 3, 1995, pp. 170-181. doi:10.1006/pest.1995.1042

[3] C. TomLin, "The Pesticide Manual," British Crop Protection Council, Surrey, 1999.

[4] M. Tomizawa and J. E. Casida, "Neonicotinoid Insecticide Toxicology: Mechanisms of Selective Action," Annual Review of Pharmacology and Toxicology, Vol. 45, No. 1, 2005, pp. 247-268.

doi:10.1146/annurev.pharmtox.45.120403.095930

[5] T. L. McTier, N. A. Evans, M. Martin-Short and K. Gration, "Comparison of the Activity of Selamectin, Fipronil and Imidacloprid against Flea Larvae (Ctenocephalides felis Felis) in Vitro," Veterinary Parasitology, Vol. 116, No. 1, 2003, pp. 45-50. doi:10.1016/S0304-4017(03)00163-8

[6] M. W. Dryden, T. M. Denenberg and S. Bunch, "Control of Fleas on Naturally Infested Dogs and Cats and in Private Residences with Topical Spot Applications of Fipronil or Imidacloprid," Veterinary Parasitology, Vol. 93, No. 1, 2000, pp. 69-75.

doi:10.1016/S0304-4017(00)00318-6

[7] V. Triantafyllidis, S. Manos, D. Hela, G. Manos and I. Konstantinou, "Persistence of Trifluralin in Soil of Oilseed Rape Fields in Western Greece," International Journal of Environmental Analytical Chemistry, Vol. 90, No. 3-6, 2010, pp. 344-356. doi:10.1080/03067310903094495

[8] X. Y. Tang, B. Zhu and H. Katou, "A Review of Rapid Transport of Pesticides from Sloping Farmland to Surface Waters: Processes and Mitigation Strategies," Journal of Environmental Sciences, Vol. 24, No. 3, 2012, pp. 351361. doi:10.1016/S1001-0742(11)60753-5

[9] M. C. Vagi, A. S. Petsas, M. N. Kostopoulou and T. D. Lekkas, "Adsorption and Desorption Processes of the Organophosphorus Pesticides, Dimethoate and Fenthion, onto Three Greek Agricultural Soils," International Journal of Environmental Analytical Chemistry, Vol. 90, No. 3-6, 2010, pp. 369-389. doi:10.1080/03067310903194980

[10] Md. Azharul Islam, V. Sakkas and T. Albanis, "Adsorption-Desorption Study of Bromophos Methyl and Quinalphos in Greek Soils," International Journal of Environmental Analytical Chemistry, Vol. 90, No. 3-6, 2010, pp. 357-368. doi:10.1080/03067310903194956

[11] B. M. Gawlik, N. Sotiriou, E. A. Feicht, S. SchulteHostede and A. Kettrup, "Alternatives for the Determination of the Soil Adsorption Coefficient Koc, of Non-Ionic Organic Compounds-A Review," Chemosphere, Vol. 34, No. 12, 1997, pp. 2525-2551.
[12] A. Walker, "A Simple Centrifugation Technique for the Extraction of Soil Solution to Permit Direct Measurement of Aqueous Phase Concentrations of Pesticide," In: J. Cornejo and P. Jamet, Eds., Pesticide/Soil InteractionsSome Current Research Methods, Institute National De La Recherce Agronomique, Paris, 2000, pp. 173-178.

[13] U. Baer and R. Calvet, "Fate of Soil Applied Herbicides: Experimental Data and Prediction of Dissipation Kinetics," Journal of Environment Quality, Vol. 28, No. 6, 1999, pp. 1765-1777. doi:10.2134/jeq1999.00472425002800060012x

[14] L. Cox, W. C. Koskinen and P. Y. Yen, "Influence of Soil Properties on Sorption-Desorption of Imidacloprid," Journal of Environmental Science and Health, Vol. B33, No. 2, 1998, pp. 123-134. doi:10.1080/03601239809373134

[15] M. Oi, "Time-Dependent Sorption of Imidacloprid in Two Different Soils," Journal of Agriculture and Food Chemistry, Vol. 47, No. 1, 1999, pp. 327-332. doi:10.1021/jf980658k

[16] W. Zheng and W. Liu, "Kinetics and Mechanism of the Hydrolysis of Imidacloprid," Pesticide Science, Vol. 55, No. 4, 1999, pp. 482-485. doi:10.1002/(SICI)1096-9063(199904)55

[17] S. K. Papiernik, W. C. Koskinen, L. Cox, P. J. Rice, S. A. Clay, N. R. Werdin-Pfisterer and K. Norberg, "SorptionDesorption of Imidacloprid and Its Metabolites in Soil and Vadose Zone Materials," Journal of Agriculture and Food Chemistry, Vol. 54, No. 21, 2006, pp. 8163-8170. doi:10.1021/jf061670c

[18] L. Cox, W. C. Koskinen, R. Celis, P. Y. Yen, M. C. Hermosin and J. Cornejo, "Sorption of Imidacloprid on Soil Clay and Organic Components," Soil Science Society of America Journal, Vol. 62, No. 4, 1998, pp. 911-915. doi:10.2136/sssaj1998.03615995006200040009x

[19] L. Cox, M. C. Hermosin, W. C. Koskinen and J. Cornejo, "Interactions of Imidacloprid with Organic- and Inorganic Exchanged Smectites," Clay Minerals, Vol. 36, 2001, pp. 267-274. doi:10.1180/000985501750177997

[20] A. S. Felsot, R. G. Evans and J. R. Ruppert, "Field Studies of Imidacloprid Distribution Following Application to Soil through a Drip Irrigation System," In: E. L. Arthur, A. C. Barefoot, and V. E. Clay, Eds., Terrestrial Field Dissipation Studies: Purpose, Design, and Interpretation, American Chemical Society, Washington DC, Vol. 842, 2002, pp. 189-205.

[21] R. C. Xuan, Q. Q. Wang, W. Zheng, H. J. Liu and W. P. Liu, "Study on the Adsorption of Imidacloprid in Soils and the Interaction Mechanism," Acta Scientiae Circumstantiae, Vol. 20, No. 2, 2000, pp. 198-201.

[22] G. A. Ahmad, J. S. Ronald, S. K. Rai and J. C. David, "The Effect of Solvent Conditioning on Soil Organic Matter Sorption Affinity for Diuron and Phenanthrene," Chemosphere, Vol. 76, No. 8, 2009, pp. 1062-1066. doi:10.1016/j.chemosphere.2009.04.027

[23] O. P. Bansal, "The Effects of Composts on AdsorptionDesorption of Three Carbamate Pesticides in Different Soils of Aligarh District," Journal of Applied Sciences \& Environmental Management, Vol. 14, No. 4, 2010, pp. 155-158. doi:10.4314/jasem.v14i4.63305 
[24] A. Pusino, M. G. Fiori, I. Braschi and C. Gessa, "Adsorption and Desorption of Triasulfuron by Soil," Journal of Agriculture and Food Chemistry, Vol. 51, No. 18, 2003, pp. 5350-5354. doi:10.1021/jf030105w

[25] T. Paszko, "Sorptive Behavior and Kinetics of Carbendazim in Mineral Soils," Polish Journal of Environmental Studies, Vol. 15, No. 3, 2006, pp. 449-456.

[26] L. Ping, C. Zhang, Y. Zhu, M. Wu, F. Dai, X. Hu, H. Zhao and Z. Li, "Imidacloprid Adsorption by Soils Treated with Humic Substances under Different pH and Temperature Conditions," African Journal of Biotechnology, Vol. 9, No. 13, 2010, pp. 1935-1940.

[27] A. J. Beck and K. C. Jones, "The Effects of Particle Size, Organic Matter, Crop Residues and Dissolved Organic Matter on the Sorption Kinetics of Atrazine and Isoproturon by Clay Soil," Chemosphere, Vol. 32, No. 12, 1996, pp. 2345-2358.

[28] M. Kumar and L. Philip, "Adsorption and Desorption Characteristics of Hydrophobic Pesticide Endosulfan in Four Indian Soils," Chemosphere, Vol. 62, 2006, pp. 1064-1077. doi:10.1016/i.chemosphere.2005.05.009

[29] J. P. Gao, J. Maguhn, P. Spitzauer and A. Kettrup, "Sorption of Pesticides in the Sediment of the Teufelesweiher
Pond (Southern Germany). I: Equilibrium Assessments, Effect of Organic Carbon Content and $\mathrm{pH}$," Water Research, Vol. 32, No. 5, 1998, pp. 1662-1672. doi:10.1016/S0043-1354(97)00377-1

[30] J. D. Fernandez-Bayo, R. Nogales and E. Romero, "Evaluation of the Sorption Process for Imidacloprid and Diuron in Eight Agricultural Soils from Southern Europe Using Various Kinetic Models," Journal of Agriculture and Food Chemistry, Vol. 56, No. 13, 2008, pp. 52665272. doi: $10.1021 / \mathrm{j} f 8004349$

[31] W. Liu, W. Zheng and J. Gan, "Competitive Sorption between Imidacloprid and Imidacloprid-Urea on Soil Clay Minerals and Humic Acids," Journal of Agriculture and Food Chemistry, Vol. 50, No. 23, 2002, pp. 6823-6827. doi:10.1021/jf0204194

[32] M. S. Bilgili, "Adsorption of 4-Chlorophenol from Aqueous Solutions by xad-4 Resin: Isotherm, Kinetic, and Thermodynamic Analysis," Journal of Hazardous Material, Vol. 137, No. 1, 2006, pp. 157-164. doi:10.1016/j.jhazmat.2006.01.005

[33] Anonym, "Imidacloprid; Pesticide Tolerances," Federal Register, Vol. 68, No. 114, 2003, pp. 35303-35315. 